\title{
Hybrid effect of basalt fiber textile and macro polypropylene fiber on flexural load-bearing capacity and toughness of two-way concrete slabs
}

\author{
Yining Ding ${ }^{\mathrm{a}, *}$, Qingxuan Wang ${ }^{\mathrm{a}}$, F. Pacheco-Torgal ${ }^{\mathrm{b}}$, Yulin Zhang $^{\mathrm{c}}$ \\ a State Key Laboratory of Coastal and Offshore Engineering, Dalian University of Technology, Dalian 116024, China \\ ${ }^{\mathrm{b}}$ University of Minho, C-TAC Research Centre, Guimaraes, Portugal \\ ${ }^{\mathrm{C}}$ University of Minho, Centre of Mathematics, Braga 4700-052, Portugal
}

\section{H I G H L I G H T S}

- The two-way slab is tested to study bi-axial flexural behaviors of TRC panel.

- Macro PP fibers may enhance the load bearing capacity in the post-peak region.

- Fiber textile and macro PP fiber show positive hybrid effect on flexural capacity.

- The hybrid use of basalt fiber textile and macro PP fiber may replace steel mesh.

- A steel-free PP fiber reinforced BTRC panel is created.

\section{A R T I C L E I N F O}

\section{Article history:}

Received 8 August 2019

Received in revised form 31 May 2020

Accepted 5 June 2020

\section{Keywords:}

Basalt fiber textile

Macro polypropylene fiber

Synergetic effect

Reinforced concrete

Tests

Load bearing capacity

Toughness

\begin{abstract}
A B S T R A C T
This paper presents an experimental study on the two-way concrete slabs with steel-free reinforcements. These include basalt fiber textile, macro polypropylene (PP) fiber and a combination of both. The plain concrete (PC) slab and steel reinforced concrete (RC) slab are studied as references. Furthermore, a comparative analysis on load bearing capacity, toughness and failure pattern of the slabs is performed. The test results indicate that the incorporation of basalt fiber textile and macro PP fibers can significantly improve load bearing capacity and toughness, and there is a positive synergetic effect between basalt fiber textile and macro PP fiber in the hybrid system. Similar to PC slab, the concrete slab reinforced with only 1-layer basalt fiber textile (BTRC1) demonstrates clearly brittle behavior. The addition of macro PP fibers may enhance the load bearing capacity in the post-peak region and convert the brittle failure pattern into a ductile one. In addition, BTRC1 slab with $8 \mathrm{~kg} / \mathrm{m}^{3}$ macro PP fibers shows higher flexural capacity than those of RC slab with a steel ratio of $0.31 \%$, and this implies that the combination of basalt fiber textile and macro PP fiber can be used to replace the steel mesh as a new type of durable reinforcement in structural members.
\end{abstract}

(c) 2020 Elsevier Ltd. All rights reserved.

\section{Introduction}

Textile reinforced concrete (TRC), a composite material made of fine-grained concrete and textile reinforcements, has received much attention in recent years due to high load bearing capacity and non-corrosive behavior of textile reinforcements. TRC shows a widely possible uses in the fields of façade system, sandwich walls, bridges, load bearing shell structures, maritime building elements, and it is also investigated as a potential structural material [1-8]. Steel reinforced concrete (RC) is considered as one of the most durable and cost-effective construction materials, but the

\footnotetext{
* Corresponding author.

E-mail address: ynding@hotmail.com (Y. Ding).
}

steel reinforcement is prone to corrosion, especially in high chloride environments, so the use of non-corrosive fiber textile as an improved alternative is expected. Compared with steel reinforcement, the corrosion resistance properties of the textile made of basalt, glass or carbon fiber can reduce the thickness of concrete covers appreciably, and a thickness of less than $10 \mathrm{~mm}$ is sufficient to ensure durability and the bond between the textile and concrete matrix $[2,3,9]$. In addition, basalt or carbon fiber reinforcements show high tensile strength which is up to six times higher than that of common-grade steel reinforcement (Fig. 1), and the elastic modulus of basalt fiber is about $40 \%$ of that of steel reinforcement; rather than fiber reinforced concrete (FRC), the fiber textile overcomes the random distribution of the chopped fibers over the total cross-section, and the rovings of the textile can be arranged in the 


\section{Notation}

PP fiber polypropylene fiber;

PC plain concrete;

RC steel reinforced concrete;

TRC textile reinforced concrete;

BTRC basalt fiber textile reinforced concrete;

BTRCi basalt fiber textile reinforced concrete slab with $i$-layer textiles, for instance, BTRC1: basalt fiber textile reinforced concrete slab with 1-layer textile;

PFRC polypropylene fiber reinforced concrete;

PFRCj polypropylene fiber reinforced concrete slab with fiber content of $j \mathrm{~kg} / \mathrm{m}^{3}$, forinstance, PFRC8: polypropylene fiber reinforced concrete slab with fiber content of $8 \mathrm{~kg} / \mathrm{m}^{3}$;
CFC fiber cocktail (i.e., basalt fiber textile and polypropylene fiber) reinforced concrete;

CFCi-j fiber cocktail reinforced concrete slab with $i$-layer basalt fiber textiles and $j \mathrm{~kg} / \mathrm{m}^{3}$ macro PP fibers, for instance, CFC1-8: fiber cocktail reinforced concreteslab with 1layer basalt fiber textile and $8 \mathrm{~kg} / \mathrm{m}^{3}$ macro PP fibers;

$M_{x} \quad$ the bending moment about $x$-axis;

$M_{y} \quad$ the bending moment about $y$-axis;

$M_{\text {crx }} \quad$ the cracking moment about $x$-axis;

$M_{\text {cry }} \quad$ the cracking moment about $y$-axis;

$\Delta F \quad$ the enhancement of load bearing capacity;

$\Delta W \quad$ the enhancement of energy absorption.

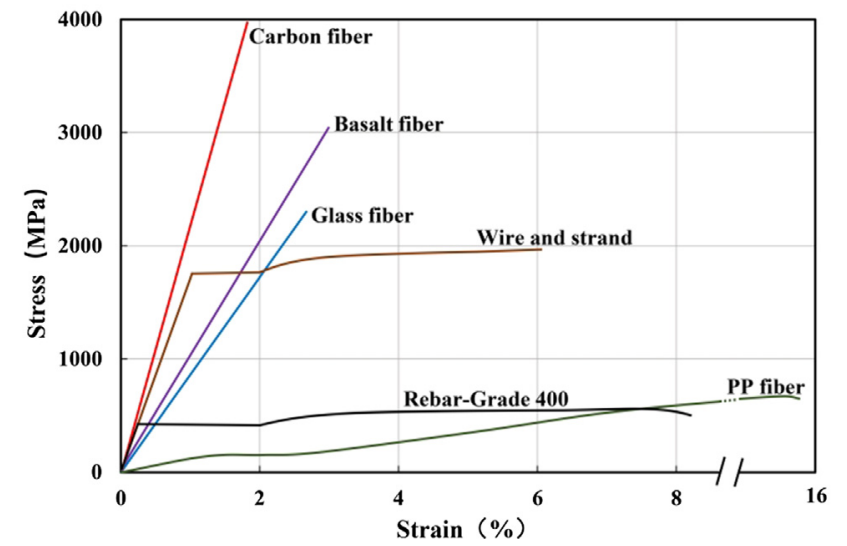

Fig. 1. Stress-strain diagram for steel rebar and basalt/carbon/glass/PP fiber.

direction of the expected tensile stresses, thus increasing the efficiency of the fiber utilization $[1,10,11]$.

Some investigations [12-20] have been performed on fiber textile (e.g. glass fiber textile, carbon fiber textile and basalt fiber textile) as a strengthening material added into concrete matrix, however, they are concentrated mainly on the uniaxial tensile and flexural properties of TRC specimen, and the literature regarding the biaxial load bearing capacity of fiber textile remains quite limited. In addition, due to the brittle nature of the basalt fiber, the incorporation of basalt fiber textile into the brittle concrete matrix might enhance the load bearing capacity of TRC, but it is hardly capable of reducing the brittleness of TRC greatly. One possible way to improve the toughness of TRC is to incorporate chopped fibers into the matrix, and some recent investigations [21-23] have verified this viewpoint, e.g., Du et al. [22] have demonstrated that micro steel fibers can improve the interfacial bonding performance between the textile and the concrete matrix as well as the shear behavior of one-way TRC slabs, thus increasing load bearing capacity and flexural toughness of the specimens. $\mathrm{Li}$ et al. [23] have concluded that the addition of macro steel fiber aids in converting the brittle failure pattern of the basalt/glass fiber textile reinforced concrete slab into a ductile one, greatly enhancing the residual load bearing capacity as well as the energyabsorption capacity of the two-way slab over the whole postpeak region. However, they mainly focus on steel fibers, and steel fibers can be corroded in the chloride environment, e.g. in coast region and for offshore structure. These facts motivate us to try TRC member using steel-free reinforcements (e.g. basalt fiber textile and macro polypropylene (PP) fiber), in order to replace the conventional RC member, which paves a new path for corrosionfree and durable structural elements. The motivation is based on the following thoughts: i) Compared with steel reinforcements (e.g. steel mesh and steel fibers), no corrosive damage on macro PP fiber would occur. Besides, macro PP fiber is capable to restrain the extension of the cracks, to moderate the stress concentration at the tip of cracks, to bridge cracks and to reduce the brittle behavior of the concrete matrix; ii) Textile reinforcements are often used as function materials, which do not take the advantage of their mechanical behavior, especially the very high bi-axial tension strength.

The objectives of two-way TRC slab under bending include a number of issues such as internal force and stress redistribution, yield line, the load transfer mechanism between the reinforcement and the concrete matrix as well as failure patterns. However, it is not intended in this study to present a complete knowledge of every aspect of the TRC slab. Indeed, the focus is given to improve the load bearing capacity and toughness of basalt fiber textile reinforced concrete (BTRC) slab by the addition of macro PP fibers, and to investigate the hybrid effect of basalt fiber textile and macro PP fiber on the load bearing capacity and energy absorption of the slabs, and to analyze failure patterns of the slabs, and to evaluate the possibility of replacing steel mesh with the fiber cocktail of basalt fiber textile and macro PP fiber as a reinforcement in the slab by comparing the experimental results of flexural behaviors including load bearing capacity, energy absorption and failure patterns.

\section{Experimental procedures}

\subsection{Materials}

The plain concrete is made with ordinary Portland cement, fly ash, regular drinking water, superplasticizer, and quartz sand as the aggregate purchased locally. The basalt fiber textile and macro PP fiber are demonstrated in Fig. 2 and Fig. 3, respectively. The physical and mechanical properties of basalt fiber textile and macro PP fiber declared by manufacturers are summarized in Table 1 and Table 2, respectively. The steel mesh is made from hot-rolled plain bars with a diameter of $6 \mathrm{~mm}$ and a spacing of $200 \mathrm{~mm}$, and the plain bar has an elastic modulus of $210 \mathrm{GPa}$, a yield stress of $300 \mathrm{MPa}$ and an ultimate stress of $420 \mathrm{MPa}$.

\subsection{Preparation of specimens}

The mixture proportions are mainly determined by the workability of fresh concrete (e.g. flow-ability, segregation resistance and uniformity of fiber dispersion), and a range of $100 \mathrm{~mm}-150 \mathrm{~mm}$ for 


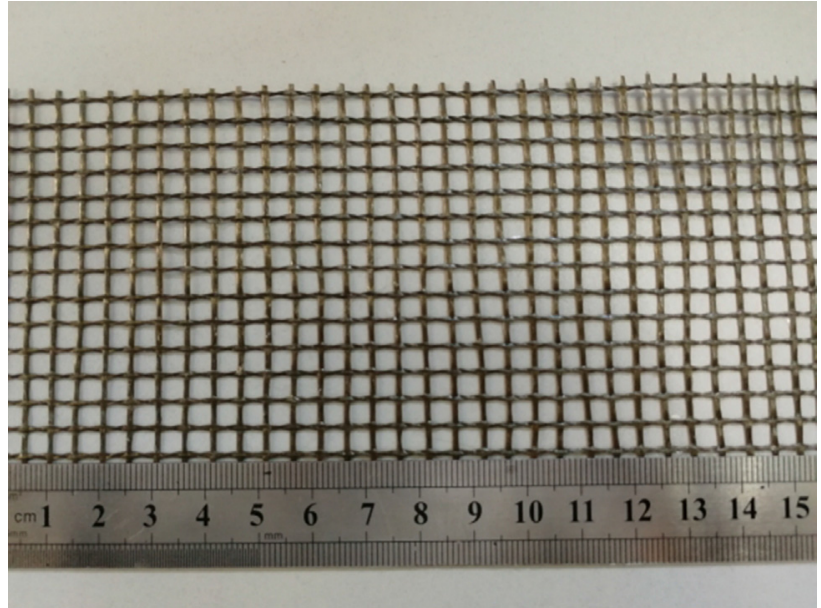

Fig. 2. Basalt fiber textile.

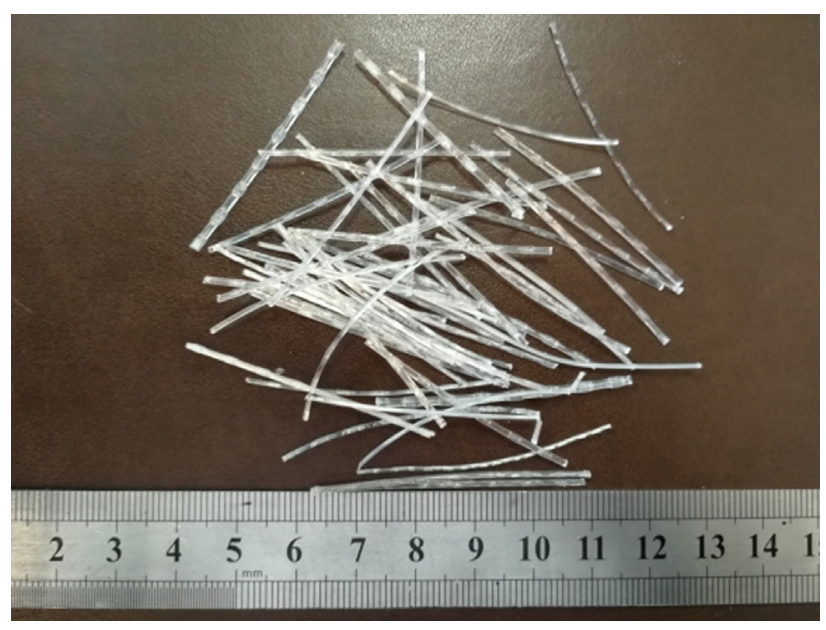

Fig. 3. Macro PP fiber.

the slump of fresh concrete is adopted according to Chinese Code GB 50164-2011 [24]. The maximum aggregate size is limited to be less than $2 \mathrm{~mm}$ due to the special geometry of basalt fiber textile (i.e., the mesh size of $5 \mathrm{~mm} \times 5 \mathrm{~mm}$ ), and the fresh concrete achieves the improved flowability and passing ability for passing through the textile grid $[1,18,22]$. The water/binder ratio is selected based on long-term research experience and previous studies, e.g., Refs. [13,22,23,25]. The base mixture of concrete is illustrated in Table 3. The 28-day compression strength of the concrete is $65.6 \mathrm{MPa}$. In order to study the hybrid effect of basalt fiber textile and macro PP fiber on the flexural property of TRC slab, basalt fiber textile and macro PP fiber are used. In this study, the number of the textile layers is 1,2 and 3 , and the fiber contents are $4 \mathrm{~kg} / \mathrm{m}^{3}, 6 \mathrm{~kg} / \mathrm{m}^{3}$ and $8 \mathrm{~kg} / \mathrm{m}^{3}$. The steel ratio of RC slab is $0.31 \%$, which is commonly used for members like roofs, facades, floors and access covers based on Chinese Code [26].

In this experiment, the manufactured specimens are two-way slabs with the size of $600 \mathrm{~mm} \times 600 \mathrm{~mm} \times 60 \mathrm{~mm}$. The concrete covers of basalt fiber textile and steel mesh are $10 \mathrm{~mm}$ and $20 \mathrm{~mm}$, respectively. For the specimens reinforced with multi-layer textiles, the spacing between the adjacent layers is $10 \mathrm{~mm}$, i.e., the depth of the second layer to the slab bottom is $20 \mathrm{~mm}$ for twolayer textiles, and the depths of the second and third layers to the slab bottom are $20 \mathrm{~mm}$ and $30 \mathrm{~mm}$ for three-layer textiles, respectively. They are prepared using the lamination technique $[21,27]$. In addition, the molds are designed to maintain moderate pre-tension in all four directions, and the purpose is to ensure that the textiles are straight in the manufacturing process. The cast specimens are demolded at a concrete age of $24 \mathrm{~h}$ and then are placed in a curing room, subsequently, the slabs are cured at 20 ${ }^{\circ} \mathrm{C}$ with $95 \%$ relative humidity up to a testing age of 28 days.

\subsection{Test methods}

To investigate the flexural behavior of TRC member, several test methods $[18-23,28]$ with regard to one-way slab and two-way slab have been developed. In this work, two-way slab test is utilized to study the biaxial flexural behavior of TRC, which yields following advantages: i) similar to steel mesh, basalt fiber textile demonstrates high biaxial tension strength, and the two-way slab test is more reasonable and exact than one-way slab test to study the effect of basalt fiber textile on the biaxial flexural behaviors of TRC slab; ii) Compared with one-way slab simply supported on two sides, the two-way slab simply supported on four edges is a three times statically indeterminate structure, and it will be subjected to bending in two directions ( $x$ and $y$ ). It allows internal force redistribution in addition to the stress redistribution during the loading process.

In this experiment, a rigid metallic frame is introduced to support the slab on its four edges and a centre point load is applied through a contact surface of $100 \mathrm{~mm} \times 100 \mathrm{~mm}$. A $1000-\mathrm{kN}$ servo-hydraulic closed loop testing machine is used and the deformation rate at the midpoint is $0.5 \mathrm{~mm} / \mathrm{min}$, as shown in Fig. 4 . In addition, as illustrated in Fig. 4(b), a digital video recorder is placed under the slab with a distance of $150 \mathrm{~mm}$ to monitor crack development of the slab. All data are synchronized and recorded using a data acquisition system.

\section{Results and discussion}

\subsection{Load bearing capacity}

In this section, the experimental results are discussed. The experiment involves testing on three reinforcement configurations,

Table 1

Properties of basalt fiber textile.

\begin{tabular}{|c|c|c|c|c|}
\hline Type & Tensile strength (MPa) & Modulus of elasticity (GPa) & Mesh size $\left(\mathrm{mm}^{2}\right)$ & Areal density $\left(\mathrm{g} / \mathrm{m}^{2}\right)$ \\
\hline Basalt fiber textile & 1710 & 96 & $5 \times 5$ & 150 \\
\hline
\end{tabular}

Table 2

Properties of macro PP fiber.

\begin{tabular}{|c|c|c|c|c|c|c|}
\hline Type & Length $(\mathrm{mm})$ & Diameter $(\mathrm{mm})$ & Aspect ratio & Tensile strength (MPa) & Elongation at break (\%) & Number (Pieces/kg) \\
\hline PP fiber & 45 & 0.8 & 56 & 456 & 16 & 559,00 \\
\hline
\end{tabular}


Table 3

Base mixture proportion.

\begin{tabular}{|c|c|c|c|c|c|}
\hline Cement $\left(\mathrm{kg} / \mathrm{m}^{3}\right)$ & Fly ash $\left(\mathrm{kg} / \mathrm{m}^{3}\right)$ & Water $\left(\mathrm{kg} / \mathrm{m}^{3}\right)$ & Water/binder ratio & Sand $\left(\mathrm{kg} / \mathrm{m}^{3}\right)$ & Superplasticizer $\left(\mathrm{kg} / \mathrm{m}^{3}\right)$ \\
\hline 504 & 126 & 210 & 0.33 & 1200 & 7.2 \\
\hline
\end{tabular}

(a)

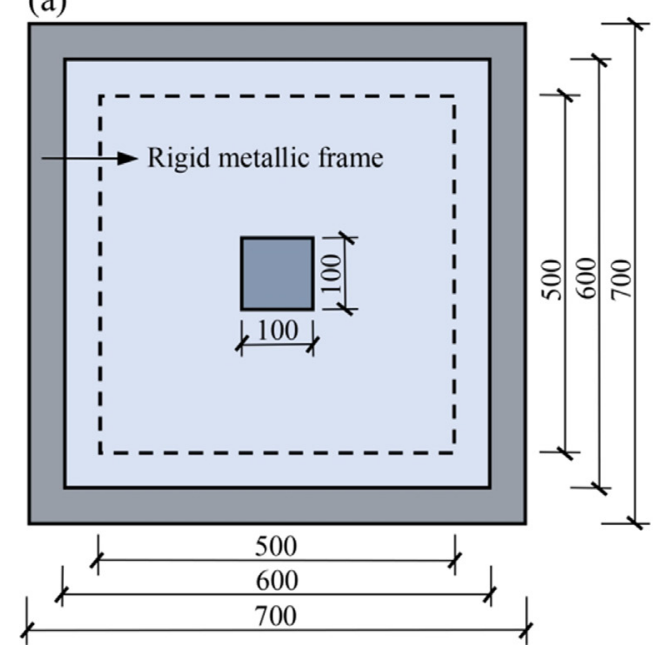

(b)

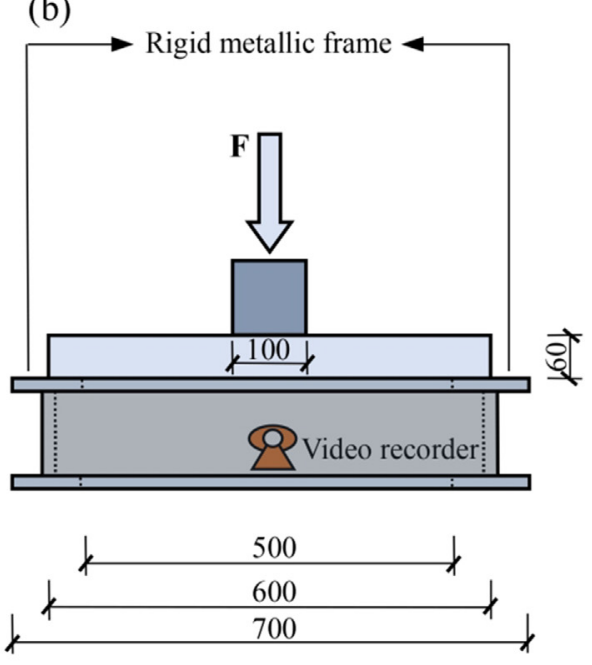

Fig. 4. Set-up for two-way slab test (dimensions in mm): (a) Top view; and (b) Front view.

namely, basalt fiber textile, macro PP fiber and hybrid use of these two materials. For each configuration, three slabs are tested, and all data used afterwards are based on the average value of the three slabs. Furthermore, the difference between the maximum (or minimum) value and the average value for the three slabs is less than $15 \%$ of the average value, which satisfies the scatter requirement for hardened concrete in Chinese Code GB/T 50081-2019 [29].

The comparison of the load-deflection curves for PC, RC and BTRC slabs is presented in Fig. 5.

As depicted in Fig. 5, the first-peak load, which is also the ultimate load of PC, is $17.5 \mathrm{kN}$ at the deflection of $0.54 \mathrm{~mm}$. Compared with PC, the first-peak load of BTRC1, BTRC2 and BTRC3 increases by $6 \%, 10 \%$ and $22 \%$, respectively, and the first-peak load of RC increases by $12 \%$. The ultimate load of BTRC1, BTRC2 and BTRC3 increases by $6 \%, 16 \%$ and $27 \%$, respectively. The ultimate load of RC increases by $35 \%$. It also can be seen that after a deflection of $3.3 \mathrm{~mm}$, the load bearing capacity of RC is higher than that of other

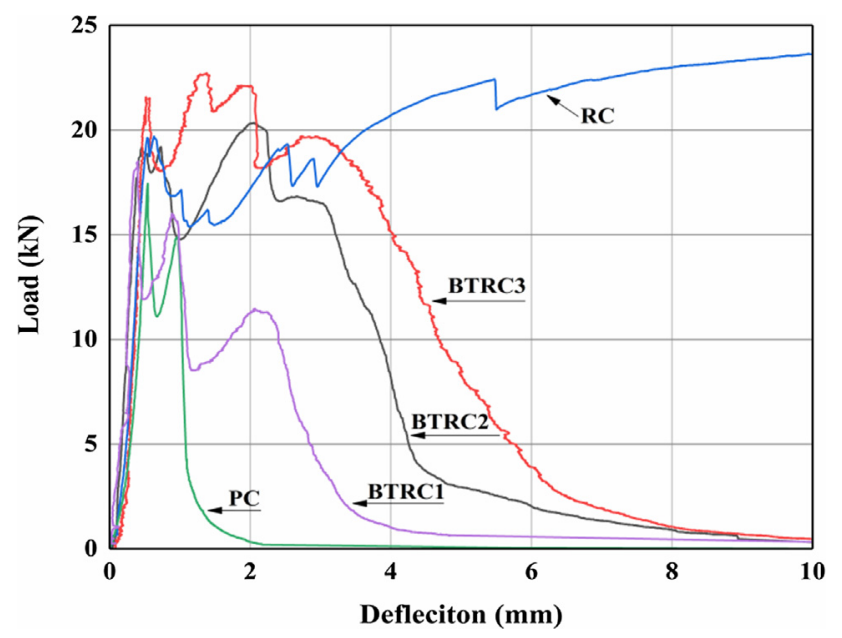

Fig. 5. Comparison of load-deflection curves for PC, RC and BTRC slabs. slabs. For RC, there is a slight decrease in the load bearing capacity at the deflection of $1.2 \mathrm{~mm}$ after the first-peak load. After that the load bearing capacity shows a gradually increasing trend and reaches approximately its ultimate value at the deflection of $10 \mathrm{~mm}$. However, for BTRC slabs, the load bearing capacity decreases rapidly with the increasing of the deflection in the post-peak region, and the BTRC slabs lose their bearing capacity after a deflection of $6 \mathrm{~mm}$.

In order to elaborate flexural behavior of two-way BTRC slab subjected to bending, the BTRC3, as a representative, is analyzed in Fig. 6. From the load-deflection curve in Fig. 6(a), it can be seen that the slab undergoes three distinct stages before the failure, and simultaneously the crack propagation process is also presented. Fig. 7 plots the tested crack pattern (dotted black lines) and the yield-line mode (dotted purple lines) for a two-way slab in the collapse state.

\subsubsection{Pre-cracking stage- $O A$}

With increasing external loading, the bending moments in two directions (i.e., $M_{x}$ and $M_{y}$, as presented in Fig. 7) increase. Before the concrete cracks, the slab behaves more or less elastically. When the load increases to $17.6 \mathrm{kN}$ at the deflection of $0.24 \mathrm{~mm}$ (point A in Fig. 6(a)), $M_{x}$ (or $M_{y}$ ) reaches the cracking moment $M_{\mathrm{crx}}$ (or $M_{\mathrm{cry}}$ ). Consequently, the outer fiber of the concrete edge at the bottom of the slab may reach the cracking strain of the concrete, and the crack is impending. A self-monitoring method [30,31] is adopted to determine cracking behaviors of concrete (e.g. cracking load and cracking time), and the results are shown in Fig. 6(b). It can be observed from Fig. 6(b) that a sudden increase in the fractional change in resistance (FCR) of concrete occurs at $93 \mathrm{~s}$, which means the initial cracking of the concrete. Correspondingly, the cracking load in the load-time curve is $17.6 \mathrm{kN}$.

\subsubsection{Post-cracking stage- $A B C D E F G$}

Crossing the point $A$, the first concrete crack occurs in the weakest section, which is assumed to be caused by $M_{\mathrm{crx}}$, as shown in Fig. 7. After the concrete cracks, the textile bridging the crack takes 

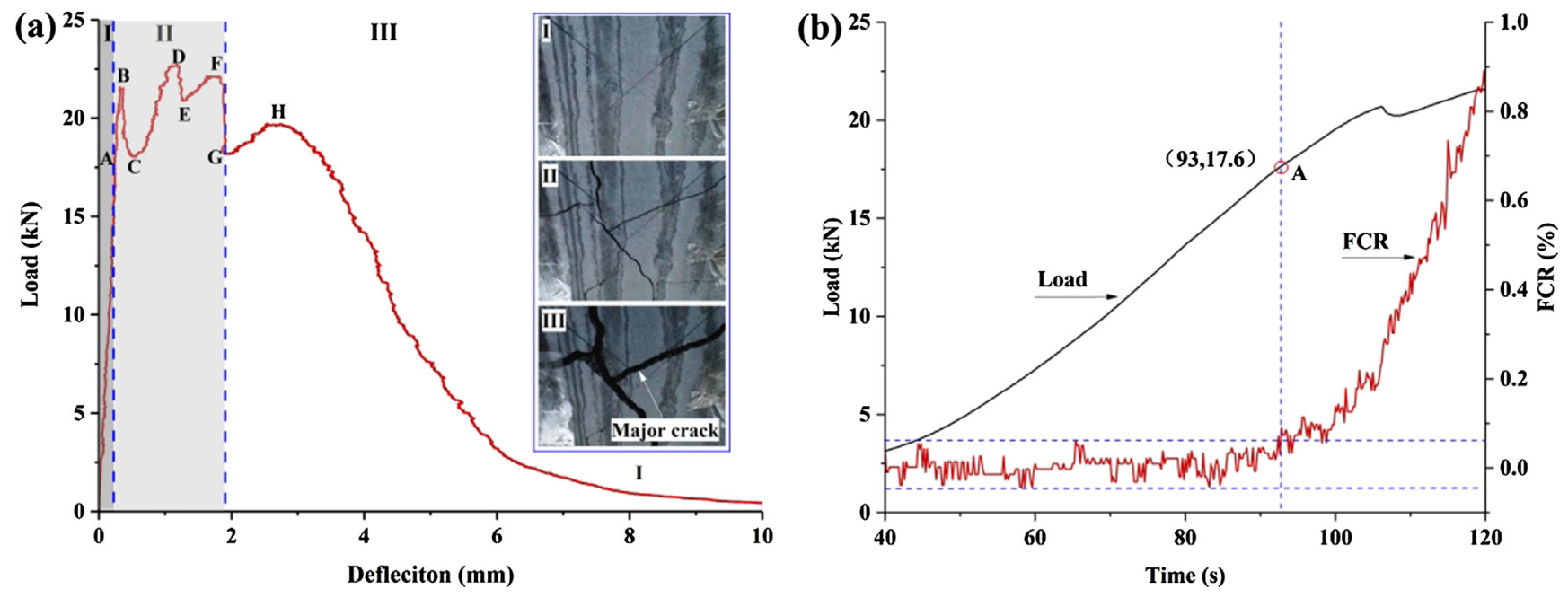

Fig. 6. Flexural response of the BTRC3 subjected to bending: (a) Load-deflection curve; and (b) Load-time-FCR curve.

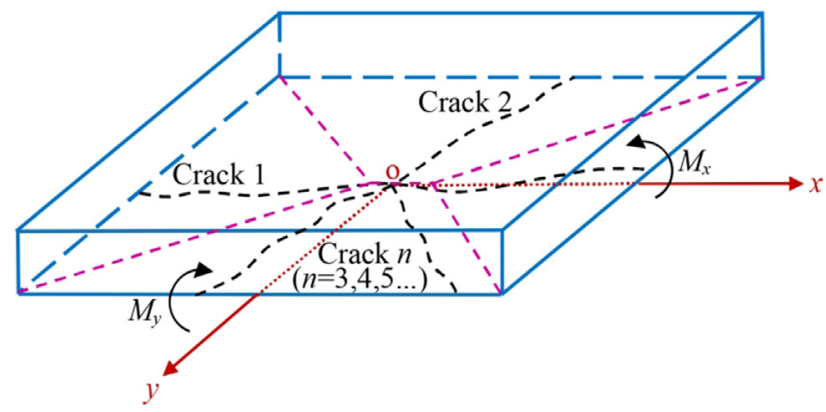

Fig. 7. Crack pattern and yield-line mode for a two-way slab in the collapse state.

up the tension released by the concrete, and meanwhile, the internal force redistributes to another direction (i.e., from $M_{x}$ to $M_{y}$ ) due to the reduction of the bending stiffness, so the load bearing capacity continues to increase (part AB in Fig. 6(a)). When $M_{y}$ reaches $M_{\text {cry }}$, a new crack (i.e., crack 2 in Fig. 7) appears, followed by a decline of about 17\% in load (part BC in Fig. 6(a)). Subsequently, the load bearing capacity increases again owing to progressive internal force and stress redistribution, and meanwhile, the cracks 1 and 2 develop and extend gradually at the bottom of the slab and the tension carried by the textile increases. When the deflection increases to $1.2 \mathrm{~mm}$, the slab reaches the ultimate load bearing capacity of $22.8 \mathrm{kN}$ (Point D in Fig. 6(a)). Then the load bearing capacity drops again (part DE in Fig. 6(a)) resulting from the formation of crack 3. This process continues with the redistribution of internal force and stress until no new crack is formed. Finally, some cracks (i.e., cracks 1 and 2) begin to develop into the major cracks, and the tension is totally resisted by the textile. This stage ends with the point $G$ at the deflection of $1.9 \mathrm{~mm}$, and the load is 18.2 $\mathrm{kN}$, with a decrease of about $20 \%$ in comparison to the ultimate load.

\subsubsection{Failure stage-GHI}

After the point $G$, the slab goes into the failure stage. At this stage, the resistance is enhanced along with crack development (part GH in Fig. 6(a)) until the formation of the collapse mechanism, i.e., the slab is divided into several regions, connected with the tensioned rovings of the textiles, by the major cracks. Subsequently, the major cracks widen and extend rapidly, and the rest of the textiles crossing the major cracks is broken down, thus lead- ing to an abrupt descending branch in the load-deflection curve (part HI in Fig. 6(a)).

Fig. 8 shows the comparison of the load-deflection curves for PC, RC and PP fiber reinforced concrete (PFRC) slabs.

As seen from Fig. 8, the first-peak loads of PFRC4, PFRC6 and PFRC 8 are $19.6 \mathrm{kN}, 23.0 \mathrm{kN}$ and $20.2 \mathrm{kN}$, respectively. Compared with PC, the increments for first-peak load of these slabs are about $10 \%, 29 \%$ and $14 \%$, respectively. Furthermore, the ultimate load is equal to the first-peak load for each tested PFRC slab.

It also can be seen that the load bearing capacity of PFRC slab shows an obvious initial increase with increasing deflection before the first-peak load, followed by a sharp decline (of more than 40\%) of load bearing capacity, and then increases gradually until a deflection of $10 \mathrm{~mm}$. When the deflection reaches $10 \mathrm{~mm}$, the residual load bearing capacity of PFRC4, PFRC6 and PFRC8 are $16.2 \mathrm{kN}, 18.6 \mathrm{kN}$ and $17.1 \mathrm{kN}$, accounting for $83 \%, 81 \%$ and $85 \%$ of corresponding ultimate loads, respectively. This high residual load bearing capacity in the post-peak region could trace back to the bridging effect of macro PP fibers which are capable to transmit tensile stresses to the matrix. Different from PFRC slab, RC indicates clear bending hardening behavior in the post-cracking region. Moreover, all the curves of PFRC slabs are approximately below that of RC over the entire deflection zone, which means that RC shows higher load bearing capacity than PFRC slabs. This behavior

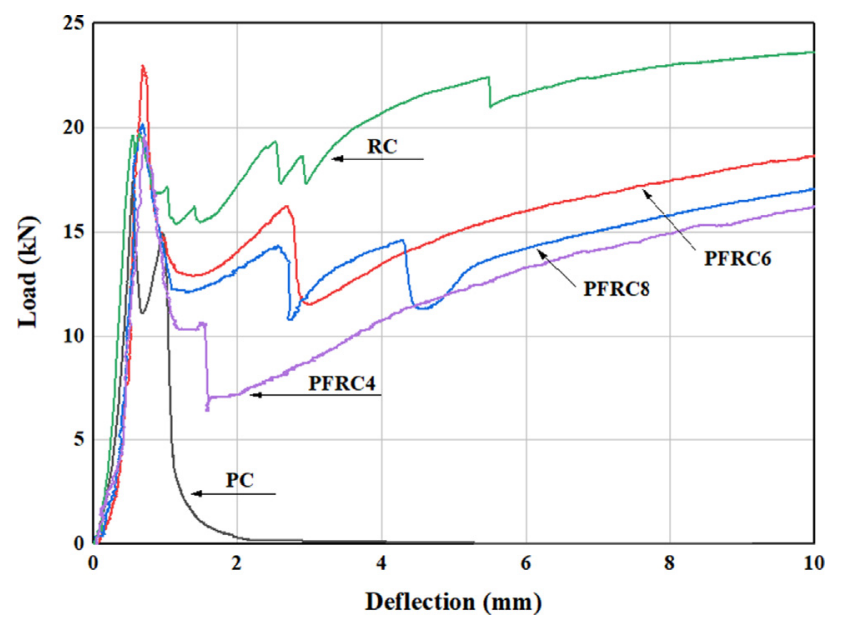

Fig. 8. Comparison of the load-deflection curves for PC, RC and PFRC slabs. 
may be attributed to the following three reasons: i) The crack pattern of RC slab follows the yield lines (Fig. 7) based on the collapse mechanism approximately, and indicates the increment of internal force redistribution in slab and improved energy absorption which is theoretically equal to the energy dissipated in the yield lines. ii) After yielding of the steel, the lever arm between the tensile force of bars and the resultant compressive force in concrete in two perpendicular directions becomes longer as the crack extends upward along the section height, leading to further increased load bearing capacity. iii) The load bearing capacity of two-way RC slabs with low steel ratio of $0.31 \%$ is greater than that of two-way PFRC slabs if the content of macro PP fiber is no more than $8 \mathrm{~kg} / \mathrm{m}^{3}$.

Fig. 9 demonstrates the comparison of the load-deflection curves for PC, RC and fiber cocktail (i.e., basalt fiber textile and polypropylene fiber) reinforced concrete (CFC) slabs.

As shown in Fig. 9, the first-peak loads of CFC1-4, CFC1-6 and CFC1-8 are $19.1 \mathrm{kN}, 20.6 \mathrm{kN}$ and $25.3 \mathrm{kN}$, and corresponding deflections are $0.52 \mathrm{~mm}, 0.47 \mathrm{~mm}$ and $0.72 \mathrm{~mm}$, respectively. The ultimate loads of CFC1-4, CFC1-6 and CFC1-8 are $22.8 \mathrm{kN}, 21.0 \mathrm{kN}$ and $25.8 \mathrm{kN}$, and corresponding deflections are $2.6 \mathrm{~mm}, 2.7 \mathrm{~mm}$ and $10.0 \mathrm{~mm}$, respectively. The residual loads of CFC1-4 and CFC1-6 at the deflection of $10 \mathrm{~mm}$ are $15.3 \mathrm{kN}$ and $13.9 \mathrm{kN}$, accounting for $67 \%$ and $66 \%$ of corresponding ultimate loads, respectively. Compared with the deflection corresponding to ultimate load of $\mathrm{PC}$, the deflections corresponding to ultimate load of CFC1-4, CFC1-6 and CFC1-8 increase about 3.7 times, 3.9 times and 17.2 times, respectively. The great deflection of CFC slabs indicates the large plastic rotation capacity around the rotation axes (i.e., the major cracks) and the high redistribution ability of internal force and stress in the slab. Compared with RC, the first-peak load and ultimate load of CFC1-8 increase by about $29 \%$ and $7 \%$, respectively.

Due to the positive effect of the fiber cocktail on the redistribution of internal force and stress, CFC slab (e.g. CFC1-8) under bending exhibits a more desirable load-deflection response than that of BTRC slab and PFRC slab. Both basalt fiber textile and macro PP fiber are capable to enhance ultimate load bearing capacity of the slab, and the ultimate load increases with the increasing number of textile layers and PP fiber content. Besides, the addition of macro PP fibers aids in enhancing the load bearing capacity in the post-peak region. The hybrid use of basalt fiber textile and macro PP fiber is much more effective in enhancing load bearing capacity than the separated use of basalt fiber textile and macro PP fiber, and the CFC1-8 shows the highest first-peak load and ultimate load compared with other slabs.

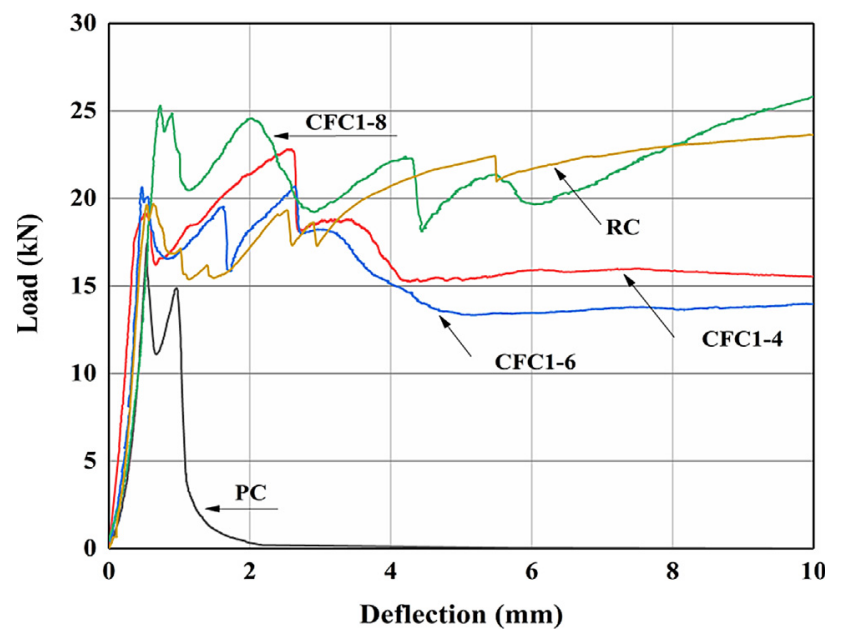

Fig. 9. Comparison of load-deflection curves for PC, RC and CFC slabs.

\subsection{Toughness}

The toughness in a slab test is usually evaluated by the energy absorption capacity $[23,32,33]$. A disadvantage of basalt fiber textile and BTRC member without macro PP fibers is the brittleness and the poor energy absorption capacity after peak loading [23]. In order to improve the energy absorption capacity of BTRC slab, macro PP fibers are incorporated into the matrix.

The energy absorption of the slab is determined in accordance with the following equation [34]:

$W_{\delta}=\int_{0}^{\delta} F(x) d x$

where $W_{\delta}$ is the energy absorption of the slab, $\mathrm{J} ; \delta$ is the deflection of the slab centre, $\mathrm{m} ; x$ is the deflection at the centre of the slab; $F(x)$ is the force corresponding to $x, \mathrm{~N}$.

For energy absorption calculation, the deflections of $1 \mathrm{~mm}$, $2 \mathrm{~mm}, 5 \mathrm{~mm}$ and $10 \mathrm{~mm}$ are selected in the range of $0 \mathrm{~mm}$ to $10 \mathrm{~mm}$. Table 4 provides a comparison of the energy absorption for PC, RC, BTRC, PFRC and CFC slabs.

From Table 4, Figs. 5, 8 and 9, the following points can be observed:

1) For the deflections of PC slab at $1 \mathrm{~mm}$ and $2 \mathrm{~mm}$, the energy absorption values are $8.4 \mathrm{~J}$ and $11.9 \mathrm{~J}$ respectively. For RC, the energy absorption values up to a deflection of $1 \mathrm{~mm}$, $2 \mathrm{~mm}, 5 \mathrm{~mm}$ and $10 \mathrm{~mm}$ are $12.6 \mathrm{~J}, 28.6 \mathrm{~J}, 87.7 \mathrm{~J}$ and $201.0 \mathrm{~J}$, respectively.

2) For BTRC slabs, the energy absorption increases with the increasing number of textile layers. The BTRC slabs exhibit higher energy absorption capacity than that of PC. The energy absorption values of BTRC2 and BTRC3 are higher than that of RC at a deflection of $1 \mathrm{~mm}$ (or $2 \mathrm{~mm}$ ), but lower than that of RC at a deflection of $5 \mathrm{~mm}$ (or $10 \mathrm{~mm}$ ). The difference between basalt fiber textile and steel mesh in improving the energy absorption can be explained as follows: i) The decreased concrete cover thickness of BTRC compared with that of RC leads to the increased effective depth of the slab. ii) The basalt fiber textile has a high tensile strength of $1710 \mathrm{MPa}$. As a result, basalt fiber textile can be more effective than steel reinforcement in improving load bearing capacity and energy absorption as the deflection is less than $2.2 \mathrm{~mm}$ (Fig. 5). However, owing to the linearelastic behavior of the basalt fiber up to failure and its lower elongation at break compared with that of the steel reinforcement, a sudden failure of BTRC occurs at the defection of less than $5 \mathrm{~mm}$, which is characterized by the rupture of the textile. On the contrary, the load-deflection curve of RC still shows deflection-hardening behavior.

3) For PFRC slabs (Fig. 8), the addition of macro PP fibers demonstrates great positive effect on the energy absorption. When the deflection reaches $2 \mathrm{~mm}$, the energy absorption for PC is $11.9 \mathrm{~J}$. Compared with PC, the energy absorption values for PFRC4, PFRC6 and PFRC8 increase by about 39\%, $96 \%$ and $88 \%$, respectively. The PC slabs are broken down brittlely from $1 \mathrm{~mm}$ up to $2 \mathrm{~mm}$, whereas the PFRC slabs continue to show the well ductility. The pronouncedly increasing energy absorption indicates that macro PP fibers demonstrate their benefits in the post-cracking behavior with the increasing of the deflection. In addition, the energy absorption of the tested PFRC slab is lower than that of RC over the entire deflection zone.

4) For CFC slabs (Fig. 9), in the case that the number of textile layers maintains constant, the energy absorption increases with the increasing of the PP fiber content. For CFC1-4, the 
Table 4

Comparison of energy absorption for PC, RC, BTRC, PFRC and CFC slabs.

\begin{tabular}{|c|c|c|c|c|}
\hline \multirow[t]{2}{*}{ Slab type } & \multicolumn{4}{|c|}{ Energy absorption $(\mathrm{J})$} \\
\hline & $W_{1}$ & $W_{2}$ & $W_{5}$ & $W_{10}$ \\
\hline PC & 8.4 & 11.9 & 11.9 & 11.9 \\
\hline $\mathrm{RC}$ & 12.6 & 28.6 & 87.7 & 201.0 \\
\hline BTRC1 & 11.4 & 21.2 & 32.4 & 34.8 \\
\hline BTRC2 & 13.6 & 31.3 & 65.9 & 72.3 \\
\hline BTRC3 & 15.7 & 38.0 & 84.6 & 94.7 \\
\hline PFRC4 & 7.4 & 16.5 & 45.7 & 117.8 \\
\hline PFRC6 & 10.1 & 23.3 & 64.6 & 149.8 \\
\hline PFRC8 & 9.9 & 22.4 & 61.6 & 138.2 \\
\hline CFC1-4 & 13.8 & 34.3 & 84.7 & 159.3 \\
\hline CFC1-6 & 8.1 & 25.8 & 76.5 & 145.0 \\
\hline CFC1-8 & 14.0 & 36.2 & 99.0 & 210.0 \\
\hline
\end{tabular}

See Notation section for abbreviations.

energy absorption values up to the deflections of $5 \mathrm{~mm}$ and $10 \mathrm{~mm}$ are $84.7 \mathrm{~J}$ and $159.3 \mathrm{~J}$, respectively. Compared with CFC1-4, the energy absorption values of CFC1-8 up to the deflections of $5 \mathrm{~mm}$ and $10 \mathrm{~mm}$ increase about $17 \%$ and $32 \%$, respectively. For CFC1-6, the energy absorption values up to the deflections of $5 \mathrm{~mm}$ and $10 \mathrm{~mm}$ are $76.5 \mathrm{~J}$ and $145.0 \mathrm{~J}$, respectively; and compared with CFC1-6, the energy absorption values up to the deflections of $5 \mathrm{~mm}$ and $10 \mathrm{~mm}$ of CFC1-8 increase about $29 \%$ and $45 \%$, respectively. CFC1-8 exhibits the highest energy absorption capacity among all slab types, and the energy absorption up to a deflection of $10 \mathrm{~mm}$ is $210.0 \mathrm{~J}$, which is $4.5 \%$ higher than that of RC. The superior load bearing capacity and toughness of CFC1-8 compared with RC indicates that the combined use of 1layer basalt fiber textile and $8 \mathrm{~kg} / \mathrm{m}^{3}$ macro PP fibers may replace the conventional steel mesh with a steel ratio of $0.31 \%$.

Based on the discussion above, it can be seen that: compared with basalt fiber textile, the macro PP fibers may show greater effect on the improvement of the energy absorption. The combined use of basalt fiber textile and macro PP fiber demonstrates the most significant positive effect on the enhancement of the postpeak property of slabs. The reasons may be traced back to different properties of reinforcing materials: i) Basalt fiber is a linear-elastic material, and a brittle failure may occur when the BTRC slab achieves the ultimate load at a small deflection [23], thus leading to modest enhancement of the energy absorption; ii) Macro PP fiber may show great deformation capacity (Fig. 1), and the elongation ratio at breaking point achieves to $16 \%$ though it shows a relatively low tensile strength. The addition of macro PP fibers may compensate the brittle property and bestow concrete with good toughness. The macro PP fibers in PFRC or CFC slabs suffer from a series of processes including debonding, slipping, pulling out or breaking down, which is accompanied by the consumption of a large amount of energy [35,36].

\subsection{Hybrid effect of basalt fiber textile and macro PP fiber}

The CFC1-8, as a representative, is studied to evaluate the possible positive synergetic effect of basalt fiber textile and macro PP fiber on load bearing capacity and energy absorption capacity.

The enhancements of load bearing capacity $(\Delta F)$ for CFC1-8, BTRC1 and PFRC8 are compared and plotted in Fig. 10. It can be seen that: i) The values of $\Delta F$ for BTRC1, PFRC8 and CFC1-8 at the deflection of $1 \mathrm{~mm}$ are $0.9 \mathrm{kN}, 0.3 \mathrm{kN}$ and $9.3 \mathrm{kN}$, respectively. Clearly, $\Delta F_{\mathrm{CFC1}-8}>\Delta F_{\mathrm{BTRC} 1}+\Delta F_{\mathrm{PFRC}}$, and $\Delta F_{\mathrm{CFC1}-8}$ is $675 \%$ greater than $\Delta F_{\mathrm{BTRC} 1}+\Delta F_{\mathrm{PFRC}}$. ii) The values of $\Delta F$ for BTRC1, PFRC8 and
CFC1-8 at the deflection of $2 \mathrm{~mm}$ are $11.3 \mathrm{kN}, 13.2 \mathrm{kN}$ and 24.6 $\mathrm{kN}$, respectively, namely,

$\Delta F_{\mathrm{CFC1}-8} \approx \Delta F_{\mathrm{BTRC} 1}+\Delta F_{\mathrm{PFRC8}}$. iii) The values of $\Delta F$ for BTRC1, PFRC8 and CFC1-8 at the deflection of $5 \mathrm{~mm}$ are $0.6 \mathrm{kN}, 12.5 \mathrm{kN}$ and $20.6 \mathrm{kN}$, respectively. Compared with $\Delta F_{\mathrm{BTRC} 1}$ plus $\Delta F_{\mathrm{PFRC}}$, the $\Delta F_{\mathrm{CFC} 1-8}$ increases by $57 \%$ iv) The values of $\Delta F$ for BTRC1, PFRC8 and CFC1-8 at the deflection of $10 \mathrm{~mm}$ are $0.3 \mathrm{kN}, 17.1 \mathrm{kN}$ and 25.8 $\mathrm{kN}$, respectively. Compared with $\Delta F_{\mathrm{BTRC} 1}$ plus $\Delta F_{\mathrm{PFRC8}}$, the $\Delta F_{\mathrm{CFC1} 1-8}$ increases by $48 \%$.

The enhancements of energy absorption $(\Delta W)$ for CFC1-8, BTRC1 and PFRC8 are compared and illustrated in Fig. 11. It can be seen that: i) The values of $\Delta W$ for BTRC1, PFRC 8 and CFC1-8 at the deflection of $1 \mathrm{~mm}$ are $3.0 \mathrm{~J}, 1.5 \mathrm{~J}$ and $5.6 \mathrm{~J}$, respectively. Compared with $\Delta W_{\text {BTRC1 }}$ plus $\Delta W_{\text {PFRC8, the } \Delta W_{-}}$ CFC1-8 increases by $24 \%$. ii) The values of $\Delta W$ for BTRC1, PFRC 8 and CFC1-8 at the deflection of $2 \mathrm{~mm}$ are $9.3 \mathrm{~J}, 10.5 \mathrm{~J}$ and $24.3 \mathrm{~J}$, respectively. Compared with $\Delta W_{\mathrm{BTRC} 1}$ plus $\Delta W_{\text {PFRC8, }}$, the $\Delta W_{\text {CFC1-8 }}$ increases by $23 \%$. iii) The values of $\Delta W$ for BTRC1, PFRC8 and CFC1-8 at the deflection of $5 \mathrm{~mm}$ are $20.5 \mathrm{~J}, 49.7 \mathrm{~J}$ and $87.1 \mathrm{~J}$, respectively. Compared with $\Delta W_{\text {BTRC1 }}$ plus $\Delta W_{\text {PFRC8, }}$ the $\Delta W_{\mathrm{CFC} 1-8}$ increases by $24 \%$ iv) The values of $\Delta W$ for BTRC1, PFRC8 and CFC1-8 at the deflection of $10 \mathrm{~mm}$ are $22.9 \mathrm{~J}, 126.3 \mathrm{~J}$ and $198.1 \mathrm{~J}$, respectively. Compared with $\Delta W_{\mathrm{BTRC} 1}$ plus $\Delta W_{\text {PFRC8, }}$ the $\Delta W_{\text {CFC1-8 }}$ increases by $33 \%$.

The discussion above indicates that the combined use of basalt fiber textile and macro PP fiber in concrete matrix demonstrates a positive synergetic effect on the load bearing capacity and energy

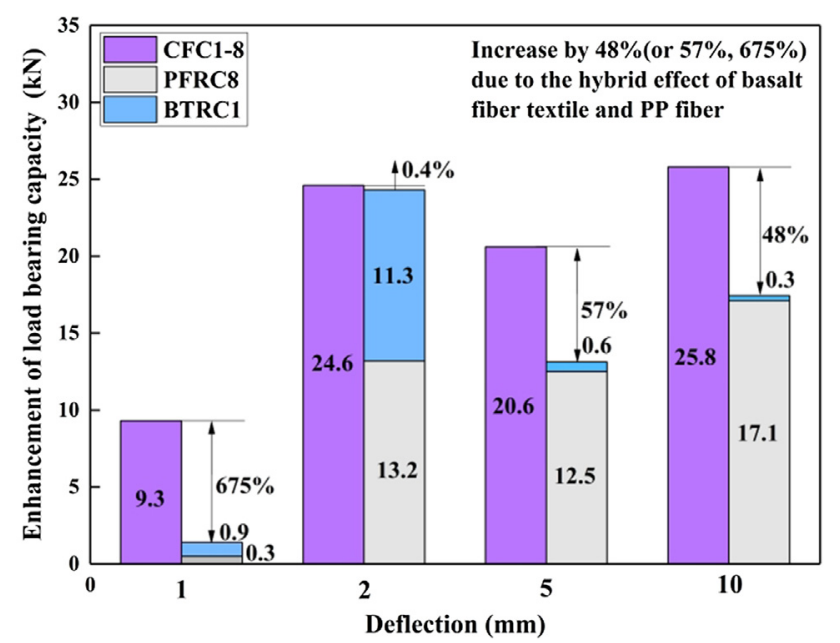

Fig. 10. Comparison of the enhancement of load bearing capacity for CFC1-8, BTRC1 and PFRC8. 


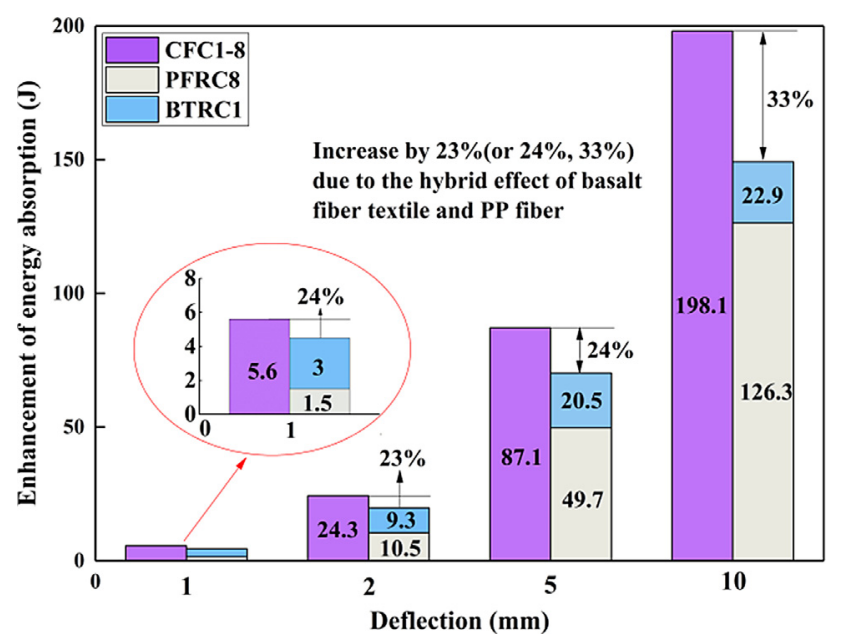

Fig. 11. Comparison of the enhancement of energy absorption for CFC1-8, BTRC1 and PFRC8.

absorption capacity of the slab, which can be explained by the following reasons: i) The strengthening mechanism of macro PP fibers in the BTRC slab is illustrated in Fig. 12. It can be seen from Fig. 12 (a) that some PP fibers (Type 1 ) added into the matrix build new "special" adhesive cross-links which provide extra connecting points to the surrounding matrix by their random positioning on the roving's surface, thus contributing to strong anchorage in the surrounding matrix, this is also evident from the literature [13]. Moreover, some fibers (Type 2) are inserted into the grids of the textile, which can improve the interfacial bonding performance between the textile and the concrete matrix [22]. Overall, both kinds of fibers (Type 1 and Type 2) contribute to improving roving-matrix bond, and the image in Fig. 12(b) provides strong support with respect to the positive effect of macro PP fibers on the roving-matrix bond. Also, some PP fibers (Type 3) across the crack in BTRC can restrain the crack propagation and cause additional stress transfer, inducing a more even stress redistribution over the cracking region than that in BTRC without PP fibers; ii) The arrangement of basalt fiber textile in the slab facilitates the two-dimensional distribution of PP fiber orientation owing to relatively thin slab thickness and the small spacing between adjacent fiber textiles [37,38], and this likely improves the structural performance of the fiber reinforced concrete [39]; iii) Basalt fiber textile and macro PP fiber act in different stress levels, and a strong positive synergy may be achieved. The combined use of basalt fiber textile and macro PP fiber in the concrete matrix can provide a more uniform redistribution of internal force and stress than the separated use of basalt fiber textile and macro PP fiber, and greatly improve the post-cracking behavior, which can be verified by the hardening behaviors (Fig. 9) and multiple cracking characteristics of the tested CFC1-8 slabs [40]. These conclusions manifest that there is a significant positive interaction between basalt fiber textile and macro PP fiber.

\subsection{Failure pattern}

The failure patterns of slabs with different reinforcements are compared and illustrated in Fig. 13. The following points can be observed:

1) The PC slab (Fig. 13(a)) shows a brittle failure mode with two major cross cracks only. Similar to PC slab, the BTRC1 slab (Fig. 13(b)) also shows a brittle failure mode due to the brittle behavior of the basalt fiber and the low textile reinforcement ratio.

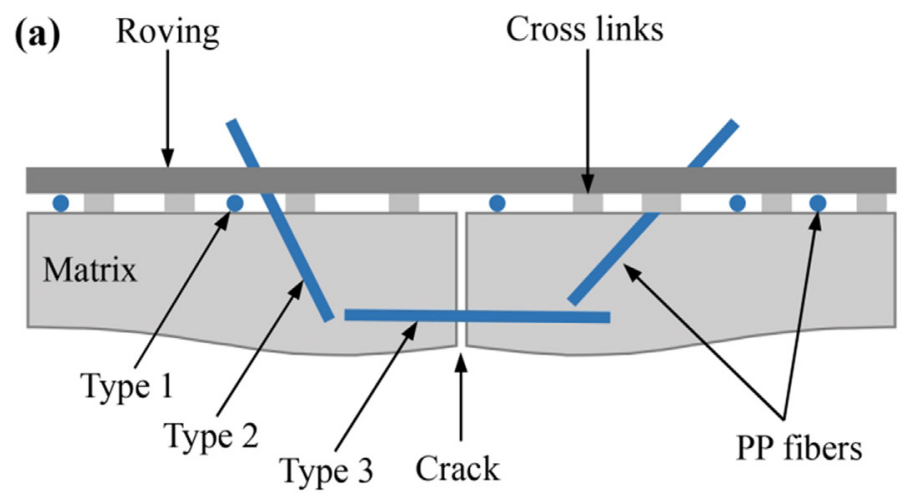

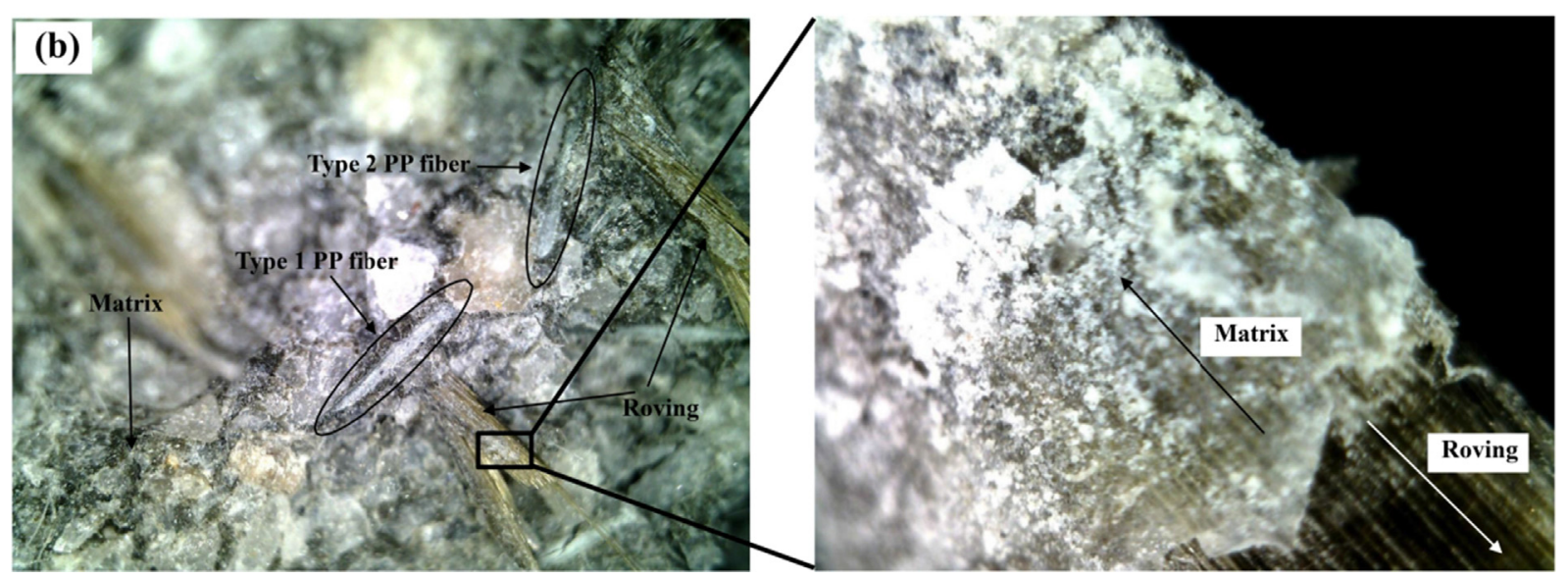

Fig. 12. Strengthening mechanism of macro PP fibers in BTRC: (a) Schematic drawing of macro PP fibers in BTRC; (b) Microscopic image of rovings in the matrix. 

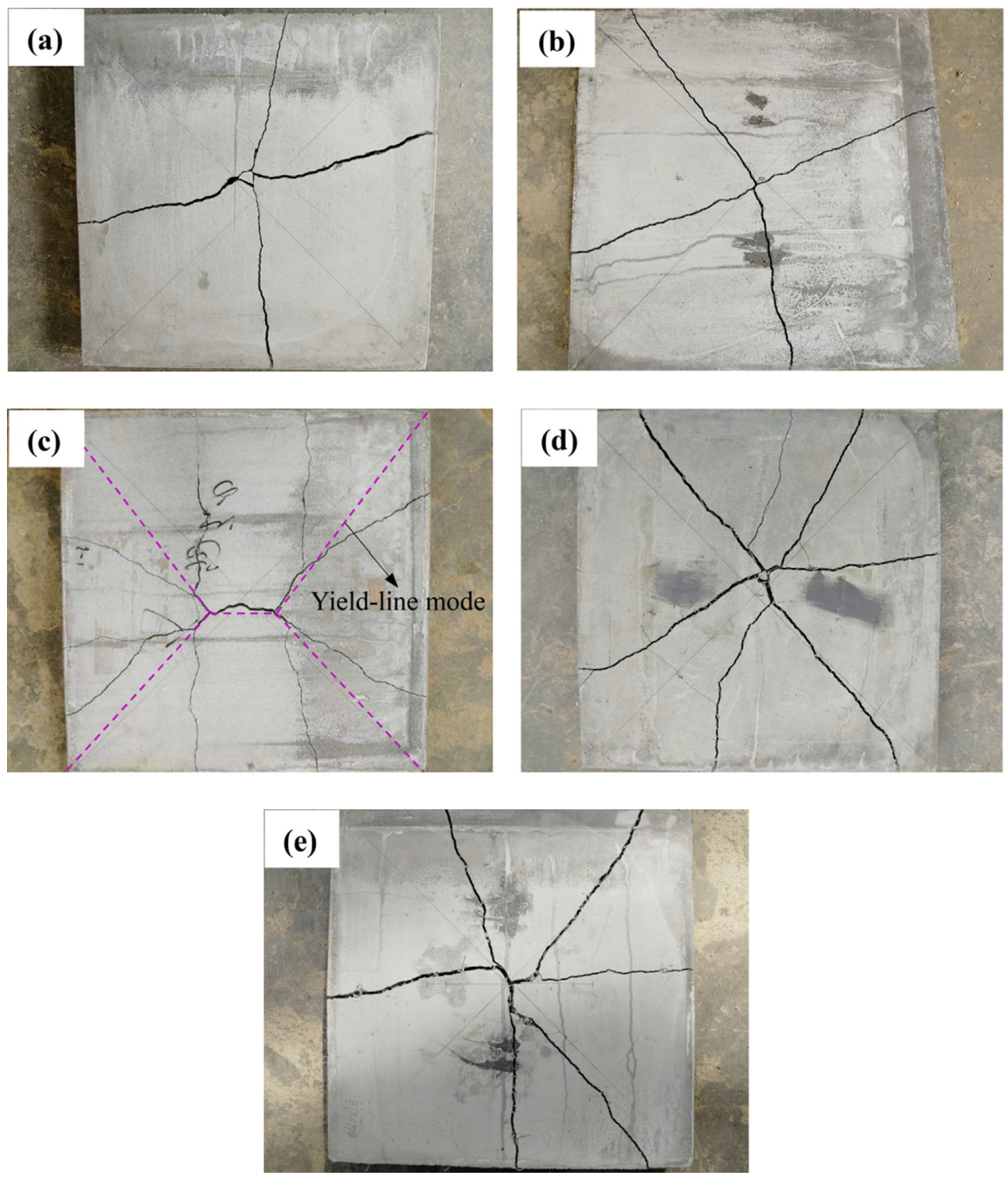

Fig. 13. Failure patterns of the tested slabs: (a) PC; (b) BTRC1; (c) RC; (d) PFRC8; and (e) CFC1-8.

2) The RC slab (Fig. 13(c)) shows a ductile failure pattern. As the load increases, the concrete cracks start from the centre of the slab, then develop diagonally towards the four corner regions, and finally form the Y-shaped cracks at the corner. This crack pattern is basically consistent with the yieldline theory $[41,42]$.

3) Similar to RC, PFRC8 and CFC1-8 exhibit the ductile failure mode characterized by a series of cracks radiating outward to the edges from the central loading area at the bottom of the slabs. Compared with the aforementioned slabs (i.e., PC and BTRC1), the crack pattern of PFRC 8 and CFC1- 8 is changed from only two major approximately cross cracks into multiple radial cracks (Fig. 13(d) and 13(e)). Meanwhile, the crack width and spacing become smaller. Additionally, the slabs after the test remain integral without penetrated cracks. The addition of the macro PP fibers aids in converting the brittle properties of the concrete into a ductile composite material.

Based on the discussion above, it can be concluded that PC and BTRC1 demonstrate clearly brittle behavior and have two major cross cracks after failure. The addition of macro PP fibers into BTRC slab changes the brittle failure pattern into a ductile one accompanied by multiple radial cracks.

\section{Conclusions}

Based on the experimental and analytical results above mentioned, the following conclusions can be drawn:

1. The load bearing capacity and toughness of the two-way plain concrete slab can be improved by the addition of basalt fiber textile. The ultimate load and energy absorption capacity of BTRC3 increase by respectively $27 \%$ and $697 \%$ compared with those of PC.

2. The addition of macro PP fibers into BTRC slab aids in enhancing the residual load bearing capacity in the post-peak region, and the residual loads of CFC1-4 and CFC1-6 at the deflection of $10 \mathrm{~mm}$ are $15.3 \mathrm{kN}$ and $13.9 \mathrm{kN}$, accounting for $67 \%$ and $66 \%$ of corresponding ultimate loads, respectively. 
3. In relation to the enhancements of load bearing capacity and energy absorption at the deflection of $1 \mathrm{~mm}$, the values of CFC1-8 are $675 \%$ and $24 \%$ greater than the sum of respective values of BRTC1 and PFRC8, respectively. It indicates that the combined use of basalt fiber textile and macro PP fiber shows a strong positive hybrid effect on load bearing capacity and toughness of the two-way slab subjected to bending.

4. The crack pattern changes from two major cross cracks of BTRC1 into a multiple radial cracks in the CFC1-8; The improved multiple cracking characteristics indicate that for basalt fiber textile reinforced concrete slab, the addition of macro PP fibers converts the brittle failure mode of slab into a ductile failure pattern.

5. Among all the tested slabs, CFC1-8 demonstrates higher load bearing capacity and energy absorption than those of RC slab with a steel ratio of $0.31 \%$. Compared with RC slab, the ultimate load and energy absorption of CFC1-8 increase by $7 \%$ and $4.5 \%$, respectively. It means that the conventional steel mesh can be replaced by the steel-free fiber cocktail of basalt fiber textile and macro PP fiber.

This work can be considered as a pioneering tentative and paves a new path for corrosion-free and durable structural members by adopting steel-free fiber cocktail (i.e., basalt fiber textile and macro PP fiber), which could be used to replace the conventional steel mesh as a reinforcement in concrete structural components. In the light of a limited number of tests performed in this study, the results should be considered as rather preliminary. A comprehensive study, however, is necessary to formulate the design principles of such objects in the future.

\section{CRediT authorship contribution statement}

Yining Ding: Conceptualization, Methodology, Writing - review \& editing, Project administration. Qingxuan Wang: Investigation, Formal analysis, Writing - original draft. F. Pacheco-Torgal: Writing - review \& editing. Yulin Zhang: Supervision, Visualization, Writing - review \& editing.

\section{Declaration of Competing Interest}

The authors declare that they have no known competing financial interests or personal relationships that could have appeared to influence the work reported in this paper.

\section{Acknowledgement}

The authors gratefully acknowledge the National Natural Science Foundation of China (Grant No. 51578109).

\section{References}

[1] J. Hegger, S. Voss, Investigations on the bearing behavior and application potential of textile reinforced concrete, Eng. Struct. 30 (7) (2008) 20502056.

[2] J. Hegger, C. Kulas, M. Horstmann, Realization of TRC facades with impregnated AR-glass textiles, Key. Eng. Mater. 466 (2011) 121-130.

[3] C. Kulas, Actual applications and potential of textile-reinforced concrete, GRCA Int. (2015) 1-11.

[4] N. Williams Portal, M. Flansbjer, K. Zandi, L. Wlasak, K. Malaga, Bending behavior of novel textile reinforced concrete-foamed concrete (TRC-FC) sandwich elements, Compos. Struct. 177 (2017) 104-118.

[5] A. Shams, M. Horstmann, J. Hegger, Experimental investigations on textile reinforced concrete (TRC) sandwich sections, Compos. Struct. 118 (2014) 643653.

[6] E. Bernat, L. Gil, P. Roc, C. Escrig, Experimental and analytical study of TRM strengthened brickwork walls under eccentric compressive loading, Constr. Build. Mater. 44 (3) (2013) 35-47.
[7] C.G. Papanicolaou, T.C. Triantafillou, M. Papathanasiou, K. Karlos, Textile reinforced mortar (TRM) versus FRP as strengthening material of URM walls: out-of-plane cyclic loading, Mater. Struct. 41 (1) (2008) 143-157.

[8] W. Brameshuber, M. Koster, J. Hegger, S. Voss, T. Gries, M. Barle, H. Reinhardt, M. kruger, Textile reinforced concrete (TRC) for integrated formworks, Special Publication 224 (2004) 45-54.

[9] N. Williams Portal, K. Lundgren, A.M. Walter, J.O. Frederiksen, L.N. Thrane, Numerical modelling of textile reinforced concrete, in Proceedings of VIII International Conference on Fracture Mechanics of Concrete and Concrete Structures, 2013.

[10] J. Hegger, N. Will, O. Bruckermann, S. Voss, Load-bearing behavior and simulation of textile reinforced concrete, Mater. Struct. 39 (8) (2006) 765776.

[11] U. Häußler-Combe, J. Hartig, Bond and failure mechanisms of textile reinforced concrete (TRC) under uniaxial tensile loading, Cem. Concr. Comp. 29 (4) (2007) 279-289.

[12] A. Peled, Z. Cohen, Y. Pasder, A. Roye, T. Gries, Influences of textile characteristics on the tensile properties of warp knitted cement based composites, Cem. Concr. Comp. 30 (3) (2008) 174-183.

[13] R. Barhum, V. Mechtcherine, Effect of short, dispersed glass and carbon fibers on the behavior of textile-reinforced concrete under tensile loading, Eng. Fract. Mech. 92 (2012) 56-71.

[14] H. Jamshaid, R. Mishra, J. Militký, M.T. Noman, Interfacial performance and durability of textile reinforced concrete, J. Text. I. 109 (7) (2018) $879-890$.

[15] N. Williams Portal, I.F. Perez, L.N. Thrane, K. Lundgren, Pull-out of textile reinforcement in concrete, Constr. Build. Mater. 71 (2014) 63-71.

[16] N. Williams Portal, K. Lundgren, H. Wallbaum, K. Malaga, Sustainable potential of textile-reinforced concrete, J. Mater. Civil. Eng. 27 (2015) 04014207.

[17] N. Williams Portal, Sustainability and flexural behavior of textile reinforced concrete, Chalmers University of Technology, Dissertations, 2013.

[18] M. Zargaran, N.K. Attari, S. Alizadeh, P. Teymouri, Minimum reinforcement ratio in TRC slabs for deflection hardening flexural performance, Constr. Build. Mater. 137 (2017) 459-469.

[19] T. Li, Y. Zhang, J. Dai, Flexural behavior and microstructure of hybrid basalt textile and steel fiber reinforced alkali-activated slag slabs exposed to elevated temperatures, Constr. Build. Mater. 152 (2017) 651-660.

[20] L.N. Koutas, D.A. Bournas, Flexural strengthening of two-way RC slabs with textile-reinforced mortar: experimental investigation and design equations, J. Compos. Constr. 21 (1) (2016) 04016065.

[21] R. Barhum, V. Mechtcherine, Influence of short dispersed and short integral glass fibers on the mechanical behavior of textile-reinforced concrete, Mater. Struct. 46 (4) (2013) 557-572.

[22] Y. Du, X. Zhang, L. Liu, F. Zhou, D. Zhu, W. Pan, Flexural behavior of carbon textile-reinforced concrete with prestress and steel fibers, Polymers 10 (1) (2018) 98.

[23] D. Li, Y. Ding, Q. Wang, Y. Zhang, Hybrid effect of fiber mesh and short fibers on the biaxial bending behavior of TRC, Mag. Conc. Res. (2018) 1-12.

[24] National Standard of the People's Republic of China, Standard for Quality Control of Concrete (GB 50164-2011), China Architecture and Building Press, Beijing, 2011 [in Chinese].

[25] B. Li, H. Xiong, J. Jiang, X. Dou, Tensile behavior of basalt textile grid reinforced engineering cementitious composite, Compos. Part B-Eng. 156 (2019) 185-200.

[26] National Standard of the People's Republic of China, Code for Design of Concrete Structures (GB 50010-2010), China Architecture \& Building Press, Beijing, 2010 [in Chinese].

[27] K. Kong, Z. Mesticou, M. Michel, A.S. Larbi, A. Junes, Comparative characterization of the durability behaviour of textile-reinforced concrete (TRC) under tension and bending, Compos. Struct. 179 (2017) 107-123.

[28] J.H. Chung, H.S. Jung, B.I. Bae, C.S. Choi, H.K. Choi, Two-way flexural behavior of donut-type voided slabs, Int. J. Concr. Struct. M. 12 (1) (2018) 26.

[29] National Standard of the People's Republic of China, Standard for test methods of concrete physical and mechanical properties (GB/T 50081-2019), China Architecture \& Building Press, Beijing, 2019 [in Chinese].

[30] Y. Ding, Z. Han, Y. Zhang, J.B. Aguiar, Concrete with triphasic conductive materials for self-monitoring of cracking development subjected to flexure, Compos. Struct. 138 (2016) 184-191.

[31] Y. Ding, G. Liu, A. Hussain, F. Pacheco-Torgal, Y. Zhang, Effect of steel fiber and carbon black on the self-sensing ability of concrete cracks under bending, Constr. Build. Mater. 207 (2019) 630-639.

[32] O. Cengiz, L. Turanli, Comparative evaluation of steel mesh, steel fiber and high-performance polypropylene fiber reinforced shotcrete in panel test, Cem. Concr. Res. 34 (8) (2004) 1357-1364.

[33] Y. Ding, W. Kusterle, Comparative study of steel fiber-reinforced concrete and steel mesh-reinforced concrete at early ages in panel tests, Cem. Concr. Res. 29 (11) (1999) 1827-1834.

[34] European Specification for Sprayed Concrete, EFNARC. Association House, 99 West Street, Farnham, Surrey, GU9 7EN, UK, ISBN 09522483 1X; 1996.

[35] S. Singh, A. Shukla, R. Brown, Pullout behavior of polypropylene fibers from cementitious matrix, Cem. Concr. Res. 34 (10) (2004) 1919-1925.

[36] N. Banthia, M. Sappakittipakorn, Toughness enhancement in steel fiber reinforced concrete through fiber hybridization, Cem. Concr. Res. 37 (9) (2007) 1366-1372. 
[37] J. Michels, D. Waldmann, S. Maas, A. Zürbes, Steel fibers as only reinforcement for flat slab construction - Experimental investigation and design, Constr. Build. Mater. 26 (1) (2012) 145-155.

[38] J. Michels, R. Christen, D. Waldmann, Experimental and numerica investigation on post cracking behavior of steel fiber reinforced concrete, Eng. Fract. Mech. 98 (2013) 326-349.

[39] D. Fall, J. Shu, R. Rempling, K. Lundgren, K. Zandi, Two-way slabs: Experimental investigation of load redistributions in steel fiber reinforced concrete, Eng. Struct. 80 (2014) 61-74.
[40] A.N. Al-Gemeel, Y. Zhuge, O. Youssf, Experimental investigation of basalt textile reinforced engineered cementitious composite under apparent hoop tensile loading, J. Build. Eng. 23 (2019) 270-279.

[41] R. Park, W.L. Gamble, Reinforced concrete slabs, John Wiley \& Sons, New York, 1980.

[42] F. Kong, R. Evans, Reinforced and prestressed concrete, third ed., Springer, Berlin, 1987. 